\title{
94 HOPING FOR THE BEST AND PREPARING FOR THE WORST: END-OF-LIFE ATTITUDES OF THE ELDERLY
}

10.1136/bmjspcare-2011-000053.94

B Kahana', E Kahana ${ }^{2}$, L Lovegreen ${ }^{2}$, J Brown ${ }^{2}{ }^{1}$ Cleveland State University, OH, USA; ${ }^{2}$ Case Western Reserve University, $\mathrm{OH}$, USA

This paper describes findings from research based on 514 elderly persons (mean age $=76.7$, SD 8.0) living in a US metropolitan community about their attitudes toward and plans for end of life care. Individual interviews reveal that most respondents were not afraid to die but feared suffering near the end of life. End of life plans were typically undertaken to protect family members from feeling burdened. The most frequently reported plans included living wills, durable power of attorney and funeral arrangements. Elders were far more likely to discuss plans with adult children and other family than with physicians or other health care professionals.

Attitudes of respondents regarding death and dying may be characterized by the adage 'hope for the best and prepare for the worst.' Accordingly, only a small minority reported often worrying about their health (13.2\%). When facing a hypothetical incurable illness, $80.3 \%$ endorsed remaining hopeful and planning activities unrelated to their illness. Similarly, $80.6 \%$ felt that people who have in incurable illness should focus on preparing for end of life issues. These elders also valued preservation of comfort through pain medications $(85.6 \%)$, being surrounded by friends and family near the end of life $(90.3 \%)$, and having others pray for them (91.8\%). The vast majority of respondents preferred to die at home, if possible $(92.3 \%)$. These data point to determination and planfulness, coupled with optimism, as elders consider the end of life. 